\title{
A Geriatric Study of Longevity Via Big Data Analytics of Metabolism, Stress and Daily Life Routine Using GH- Method: Math-Physical Medicine
}

\author{
Gerald C. Hsu \\ eclaireMD Foundation, USA.
}

*Corresponding Author: Gerald C. Hsu, eclaireMD Foundation, USA.

\section{INTRODUCTION}

This paper describes the author's theory and daily practice of preventive medicine via big data analytics based on a quantitative and precision medicine approach. Undeniably, diet, exercise and details of medical conditions are important to longevity; however, he decided to address the overall root causes of various chronic diseases, with a special emphasis on two vital factors, stress and daily life routine regularity which have been greatly ignored. In this particular article, he includes his macro-view relationship between life longevity and overall metabolic status.

\section{METHODS}

The author has spent $\sim 30,000$ hours over the past 10 years (2010-2020) to conduct his research on metabolism, endocrinology, and chronic diseases and complications, especially diabetes and glucoses.

In the beginning, from 2010 to 2013, he self-studied internal medicine and food nutrition. He specifically focused on six chronic diseases, i.e. obesity, diabetes, hypertension, hyperlipidemia, cardiovascular disease (CVD) \& stroke, and chronic kidney disease (CKD). In 2014, he allotted the entire year to develop a complex mathematical metabolism model which includes 4 output categories (weight, glucose, blood pressure, lipids) and 6 input categories (food, water, exercise, sleep, stress, life routine regularity). There are about 500 detailed elements included in these 10 categories. Since using a theoretical approach to deal with a dataset of 10 categories with 500 elements, the problem of identifying and solving all possible interactive relationships among them would be an immense task. This task would include complicated calculations of 500 ! steps. This kind of approach is a huge undertaking without any obvious benefit; therefore, he adopted an approach of applying mathematical concept that is topology. In addition, he applied a practical engineering modeling technique such as finite element method to seek a quicker but rather accurate solution for this complicated biomedical system. At the end, he was able to develop a mathematical metabolism model embedded in a specially designed application software on the iPhone ("eclaireMD") for his daily use in order to maintain his health status and also serve as a useful research tool for his ongoing various medical research projects. During the development process, he has defined two more new variables, metabolism index (MI) and general health status unit (GHSU), where GHSU is the 90-days moving average MI that is similar to HbA1C's 90-days moving average glucoses. The results of this dynamic model can be expressed through these two newly defined variables, MI and GHSU, to describe a person's overall health status and shortcomings in any specific area at any moment in time.

In lifestyle management domain, food, water intake, and exercise directly affect medical conditions related to chronic diseases. Sleep is also extremely important, particularly in strengthening the immune system to fight against many disorders, including chronic diseases, cancers, and infectious diseases. However, stress and daily life routines are two significant rootcausing categories of health problems, which can be hidden and overlooked. The author studied and researched psychology for 9-years before focusing on internal medicine. He understood the close linkage between the psychological factors and physiological factors. He has already written a few papers in this area. Besides, many research studies have shown the direct linkage between longevity and regular daily life routines. As a result, he included sleep and daily routines in his study of geriatrics and longevity. 
A Geriatric Study of Longevity Via Big Data Analytics of Metabolism, Stress and Daily Life Routine Using GH-Method: Math-Physical Medicine

Although his input data collection for this metabolism model started on $1 / 1 / 2012$, the input data regarding both stress and daily life routines started two years later, on 4/19/2014. It took him almost three years before he could finish the design and development of a complete scope of his metabolism model. For example, the stress category alone took almost two years to complete. This stress category includes about $40+$ elements with $\sim 50 \%$ for normal person and $\sim 50 \%$ for people who suffered from various personality disorders (a total of 14 different kinds of personality disorders). These two group of people would be triggered by different external stressors and then respond with varying degrees of internal stress stimulation. For example, for a normal person, stressors can be caused from work, family, social relationships, external events, or environment. Each person would react to stressors with various types and degrees of response. For the "abnormal psychology" area, it could involve flashbacks of trauma, rage, mood swings, fear of abandonment, deep shame, or substance dependency. All of the above are included in his stress sub-system since he does not know how many different types of users in the future will utilize his metabolism system.

\section{RESULTS}

Although his initial input data were collected since $1 / 1 / 2012$ (Figure 1), for this particular study, the author separates his entire time span of 8.5 years into the following five periods.

Period A: out-of-control period

$1 / 1 / 2012-4 / 18 / 2014$

Period B: initial stage of control

$4 / 19 / 2014-12 / 31 / 2016$

Period C: a better performed year

$1 / 1 / 2017-12 / 31 / 2017$

Period D: busy on speech traveling

$1 / 1 / 2018-1 / 18 / 2020$

Period E: COVID-19 quarantine

$1 / 19 / 2020-6 / 24 / 2020$

The following lists four performance scores which are expressed in the percentage format and arranged in the following order:

\section{MI/GHSU/Stress Level/Life Routine}

Period A (Figure 1) is the "out-of-control" period $(1 / 1 / 2012-4 / 18 / 2014)$. It was before he developed his metabolism model and acquired all the necessary medical knowledge. As a result, Period A's performance scores were the highest (worst performance). He did not enter any data related to stress and daily life routines, therefore there are no results available during this initial stage of his research.

MI/GHSU/Stress Level/Life Routine Period A: 92\% / 92\% / NA / NA

Period B (Figure 2) is the initial trial period (4/19/2014 -12/31/2016). During this time, he was still learning about chronic diseases and metabolism. Therefore, his overall performance scores were the second highest (i.e. the second worst).

MI/GHSU/Stress Level/Life Routine. Period B: 64\% / $66 \% / 55 \% / 74 \%$

Period C (Figure 3), the year 2017 (1/1/2017 $12 / 31 / 2017$ ) is the author's much lower performance $\%$ period (means better performance).

MI/GHSU/Stress Level/Life Routine. Period C: $57 \%$ / $57 \% / 50 \% / 73 \%$

Period D (Figure 4), from 1/1/2018 through $1 / 18 / 2020$, is the slightly higher performance score $\%$ period (means "not-so perfect" performed) than Period C. During this period D, he traveled to $50+$ international cities, attended $60+$ medical conferences worldwide, and made 100+ oral presentations of his medical papers. In summary, during this period $\mathrm{D}$, he overworked himself at the cost of damaging his overall health conditions, possibly even shortening his life expectancy to some degree.

MI/GHSU/Stress Level/Life Routine. Period D: 58\% / $58 \% / 50 \% / 74 \%$

Period E (Figure 5), from 1/19/2020 through $6 / 24 / 2020$, is the lowest performance score \% (means best performed). This period coincides with the COVID-19 quarantine period. He stays at home, eats all home-cooked meals with balanced nutritional ingredients, exercises on a regular schedule, maintains a high quality sleep (minimum of 7 hours and wakes up only once per night), drinks 3,000 cc water each day, enjoys a stress-free life (avoids being disturbed by bad news regarding virus death and nasty politics), and keeps a regular daily life routine. 
A Geriatric Study of Longevity Via Big Data Analytics of Metabolism, Stress and Daily Life Routine Using GH-Method: Math-Physical Medicine

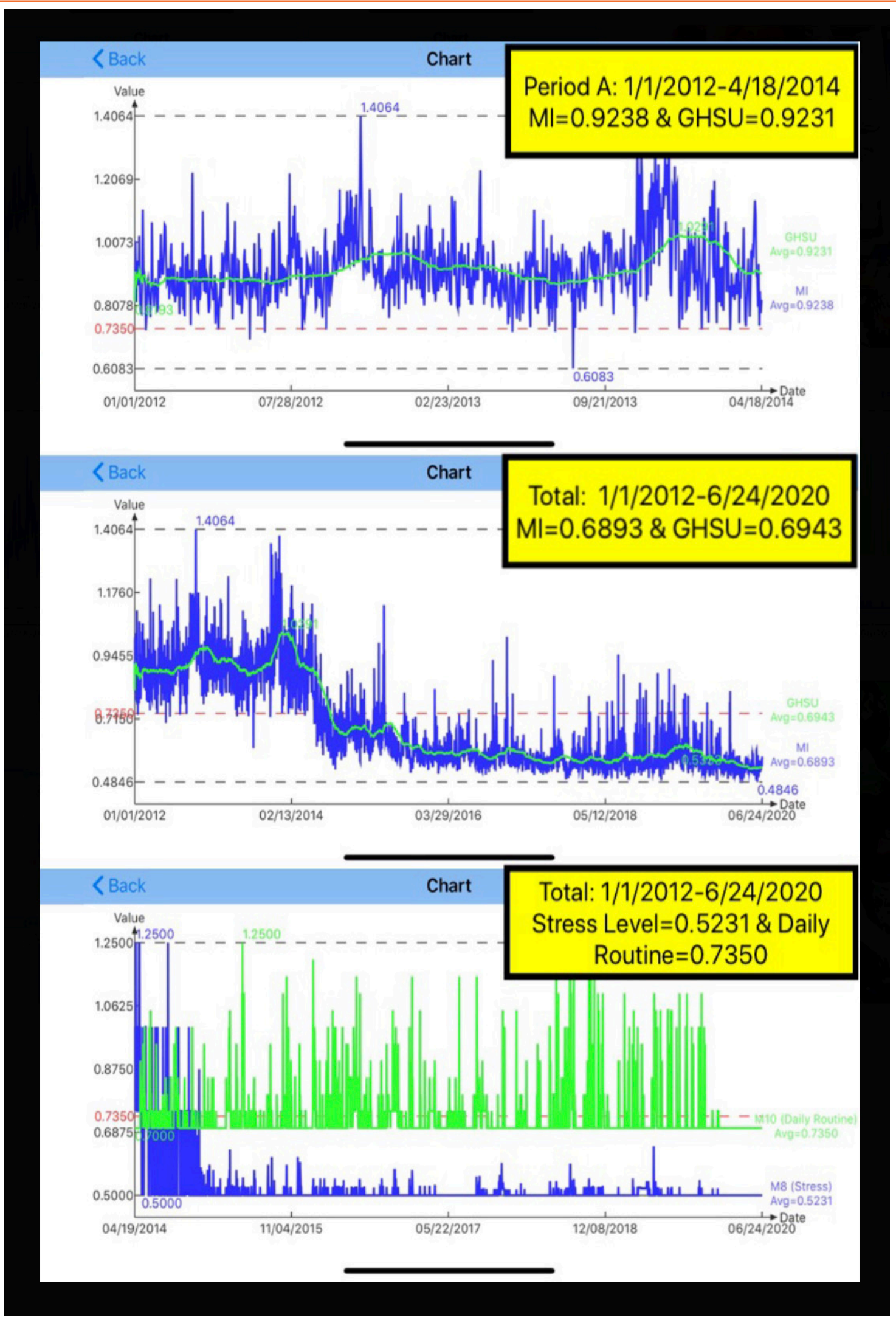

Figure1. Period A from 1/1/2013 to 4/18/2014 \& Total Period from 1/1/2012 to 6/24/2020 
A Geriatric Study of Longevity Via Big Data Analytics of Metabolism, Stress and Daily Life Routine Using GH-Method: Math-Physical Medicine

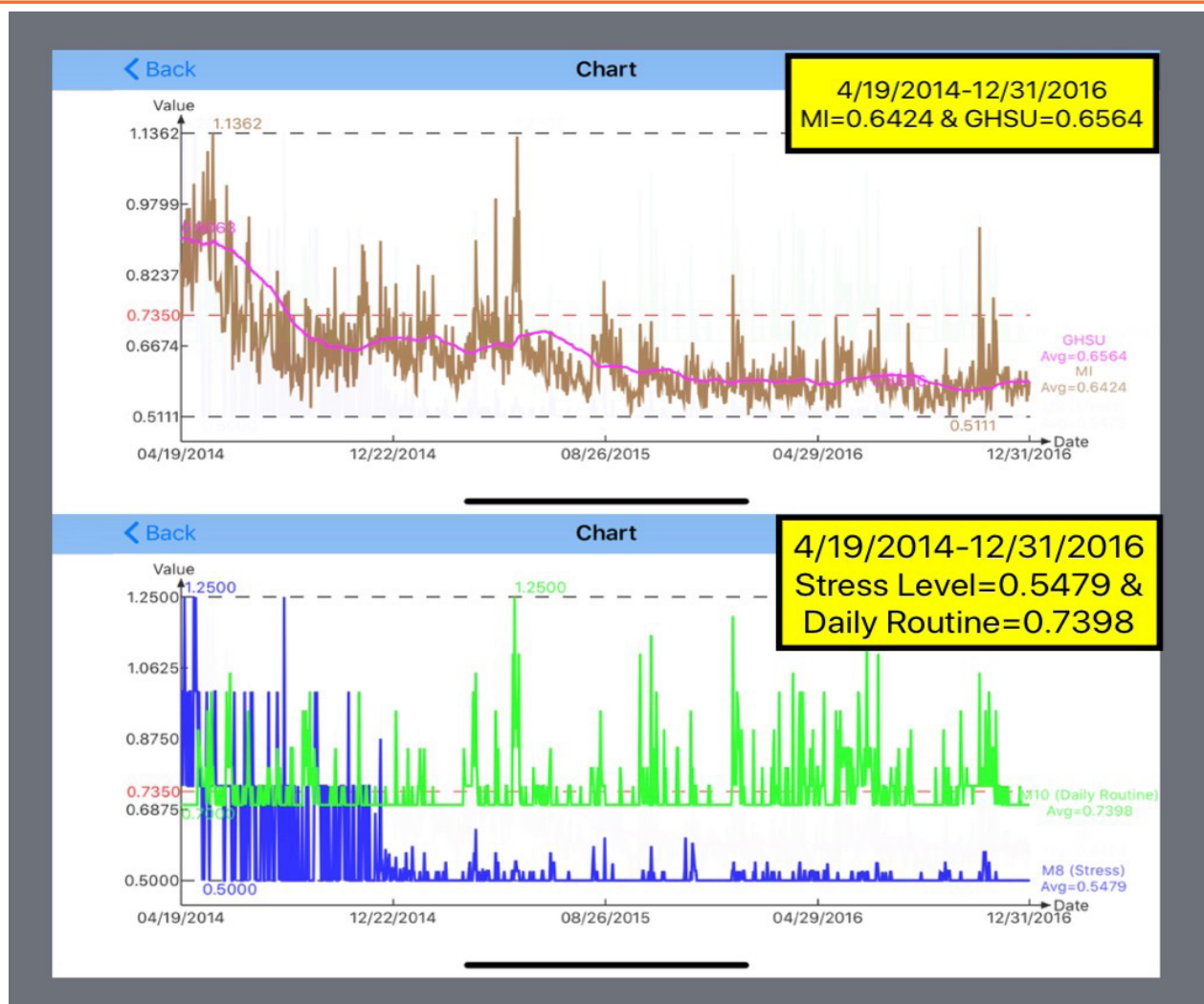

Figure2. Period B from 4/19/2014 to 12/31/2016

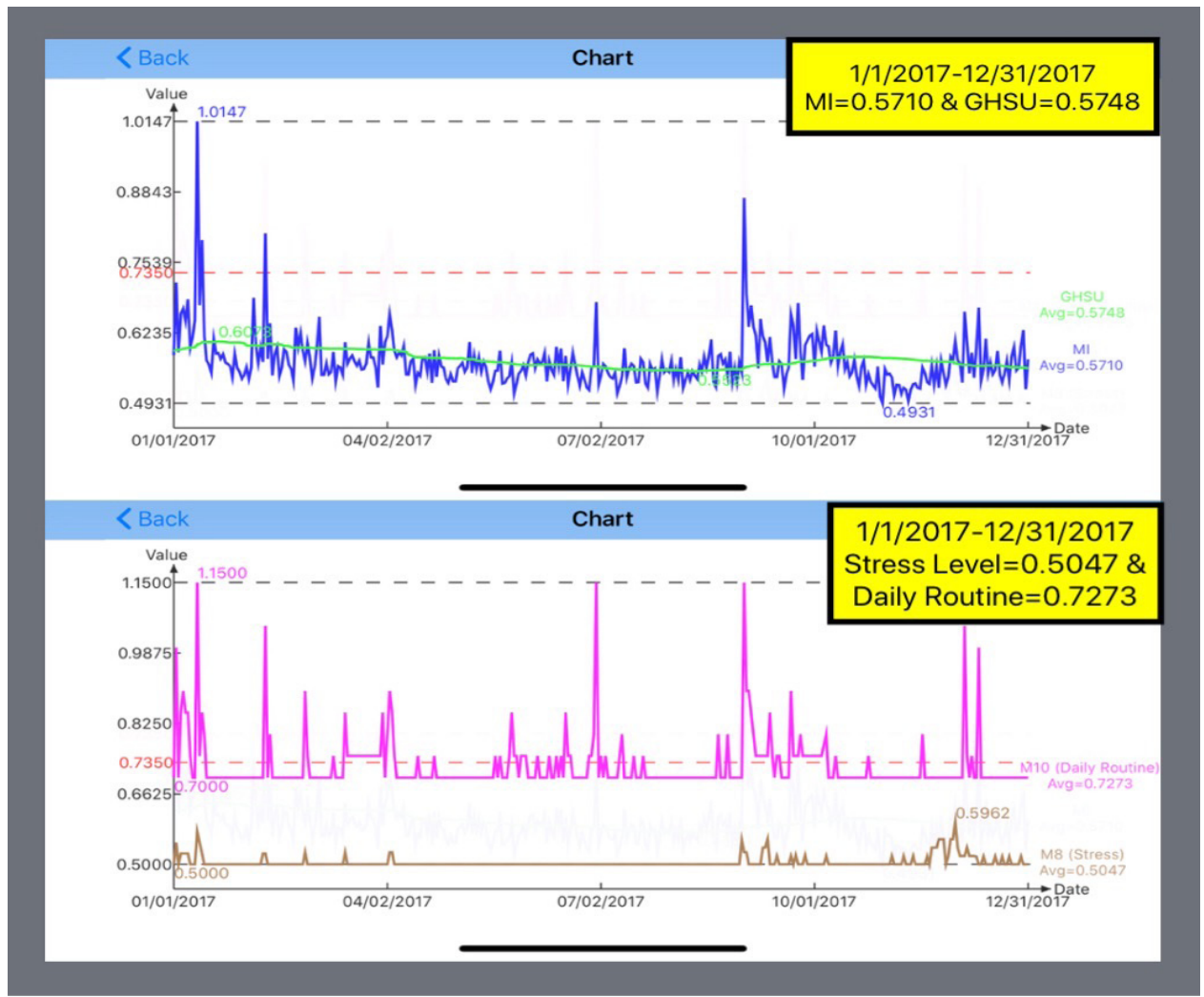

Figure3. Period C from 1/1/2017 to 12/31/2017 
A Geriatric Study of Longevity Via Big Data Analytics of Metabolism, Stress and Daily Life Routine Using GH-Method: Math-Physical Medicine

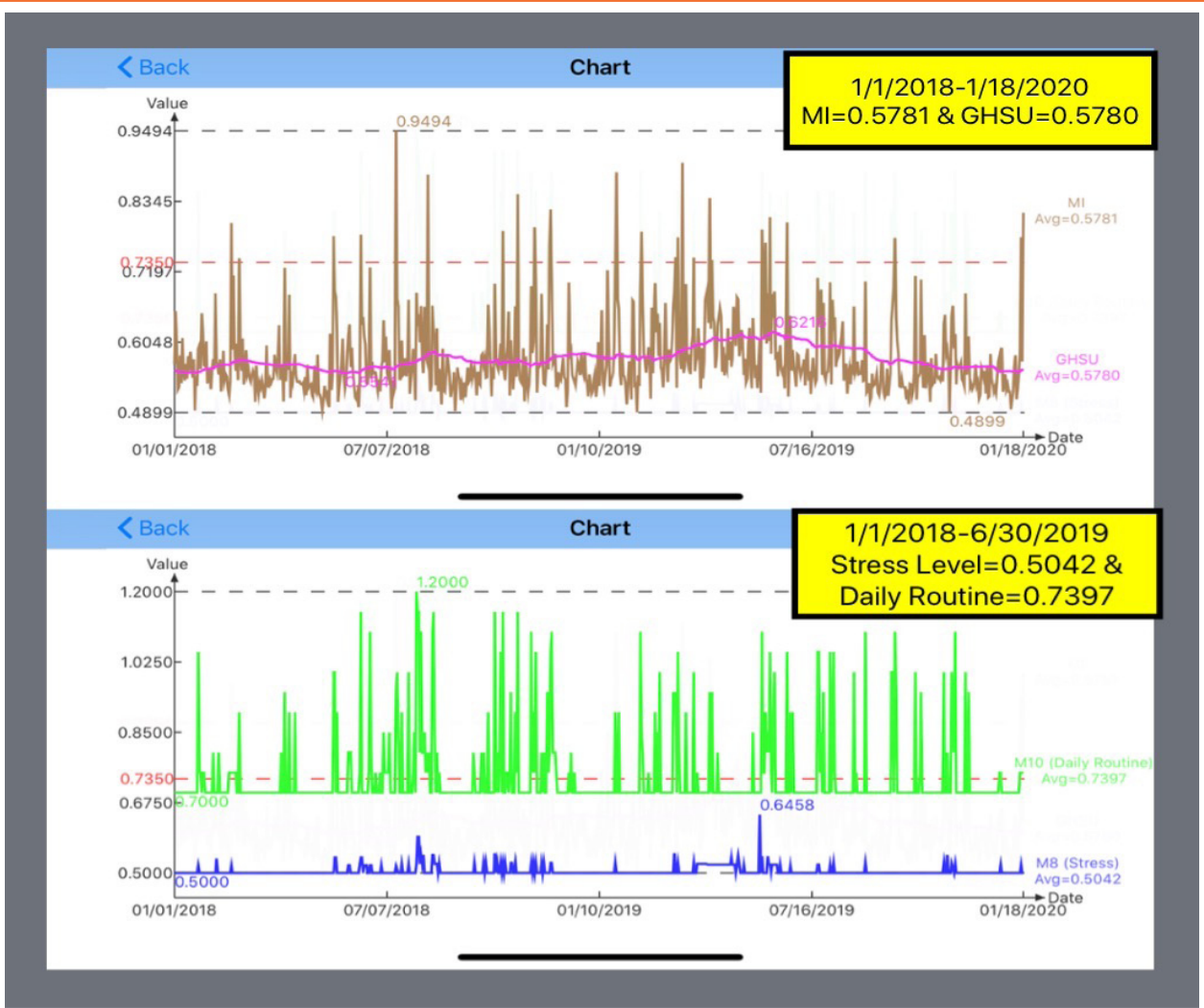

Figure4. Period D from $1 / 1 / 2018$ to $1 / 18 / 2020$

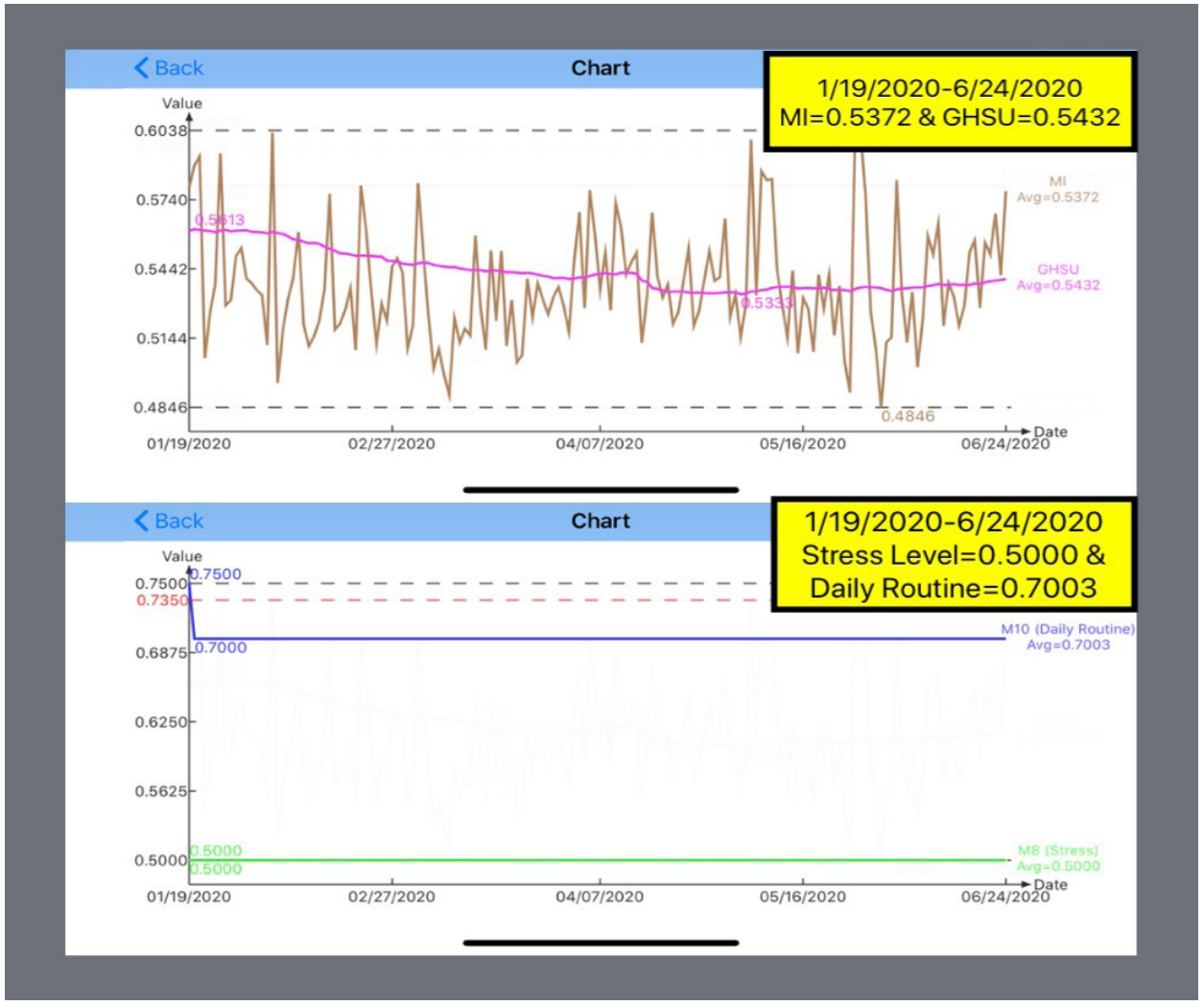

Figure5. Period E from $1 / 19 / 2020$ to $6 / 24 / 2020$ 
A Geriatric Study of Longevity Via Big Data Analytics of Metabolism, Stress and Daily Life Routine Using GH-Method: Math-Physical Medicine

MI/GHSU/Stress Level/Life Routine. Period E: 54\% / $54 \% / 50 \% / 70 \%$

During Period D and Period E, these 30-months (905 days), he has written a total of 282 medical papers with $200+$ have already been published in various medical journals. His busy medical research work does not hurt his health conditions since it is his personal hobby, not his ways or means to make-aliving. However, the medical research associated with a busy travel schedule would certainly hurt him to some degree - $4 \%$ of extra damage to his MI, GHSU, and daily life routines, but do not affect his stress conditions at all.

Figure 6 shows both the data table of numerical comparison and a bar chart of performance percentages against baseline conditions. From this Figure 6, you can see his health trend for the past
8.5 years clearly, which is similar to looking at a road map of his past 8.5-year journey. In his metabolism calculations, he specifically adopted $73.5 \%$ as the baseline for both MI and GHSU, healthy if $<73.5 \%$ and unhealthy if $>73.5 \%$. He also adopted $50 \%$ as the best possible condition for stress level and $70 \%$ as the best possible condition for daily life routines.

From Figure 6, Period A has the worst performance scores of $92 \%$ for both MI and GHSU and $126 \%$ when comparing against the baseline of $73.5 \%$. Period E has the best performance scores of $54 \%$ for both MI and GHSU and 73\%-74\% when comparing against the baseline of $73.5 \%$. In summary, both of his overall health status, MI and GHSU, as well as two specific categories of stress level and life routines, have been improved by $70 \%$. This remarkable improvement will definitely contribute on his perspective of longevity.

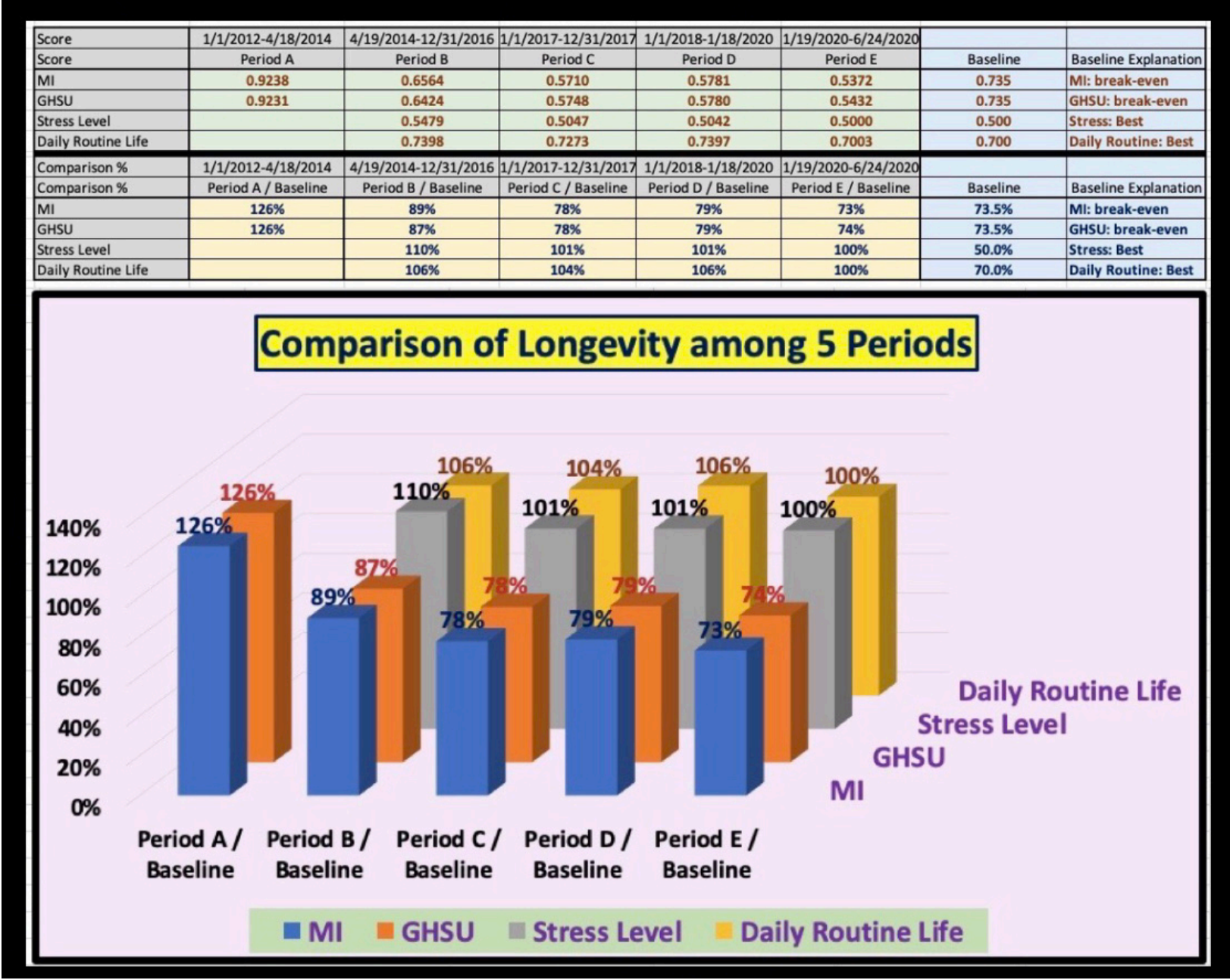

Figure6. Comparison among Periods $A, B, C, D$, and $E$ (MI, GHSU, Stress, and Daily routine) 
A Geriatric Study of Longevity Via Big Data Analytics of Metabolism, Stress and Daily Life Routine Using GH-Method: Math-Physical Medicine

All performance scores of Periods B, C, and D are located between the upper bound of Period A and the lower bound of Period E. This means that his overall health conditions and stress/life routines are improving year after year toward a better situation. Giving this improvement scenario of metabolism and health, his probability of achieving his longevity has also earned some extra degree of reassurance.

Mostmedical research results have shown thatmajority of people with long lives lived a simple but routine lifestyle. Therefore, we should focus on the category of "daily life routine regularity". His performance score for this specific category has increased (i.e. worsen) by $2 \%$ during Period D. More specifically, this increased performance score (i.e. worsen conditions) is the combined end results from air-flights, hotel meals and life, disturbance of food and exercise routines, weather changes, living environment changes, jet lag, and sleep pattern disturbance.
It is quite interesting to find out that his stress level has been at a near perfect condition (performance scores at 50\%) from Period C through Period E. In other words, he has lived in a "stress-free" life since $1 / 1 / 2017$. This is probably due to the fact that medical research work is his personal hobby. For most working people, their jobs are their ways and means to make a living with a specific purpose of gaining fame, power, or money. In other words, he has not suffered any stress from a "boss" or "deadlines" from his medical research projects like most working people at their normal jobs.

The list of daily life routine is shown in Figure 7 which has many items to be concerned about. Therefore, it is quite difficult to achieve a perfect score in this daily life routine category. His performance score of life routine was 74\% in Period B of 2017 and continuously decreased to $70 \%$ (a perfect score) in Period E of 2020.

\begin{tabular}{|c|c|c|}
\hline $\begin{array}{c}06 / 25 / 2020 \\
M I=0.7628 \quad \text { GHSU }=54.4 \%\end{array}$ & 2 & \\
\hline $\begin{array}{ll}\text { Stress } & \text { Food \& Meal }\end{array}$ & \multicolumn{2}{|c|}{ Daily Routine } \\
\hline \multicolumn{3}{|l|}{ Are the following items out-of-order? } \\
\hline Short Air Travel Today & Yes & No \\
\hline Long Air Travel Today & Yes & No \\
\hline Trauma Today & Yes & No \\
\hline Job \& Work & Yes & No \\
\hline Rest \& Leisure & Yes & No \\
\hline Exercise \& Fitness & Yes & No \\
\hline Food \& Meal & Yes & No \\
\hline Disease, Discomfort, Fatigue & Yes & No \\
\hline Hay Fever \& Allergy & Yes & No \\
\hline Weather \& Living Environment & Yes & No \\
\hline Jet Lag & Yes & No \\
\hline Sleep Pattern Disturbance & Yes & No \\
\hline Urination \& Bowel Movement & Yes & No \\
\hline Brain Exercise & Yes & No \\
\hline Meditation & Yes & No \\
\hline \multicolumn{3}{|l|}{ Environmental Factors for Cancer: } \\
\hline Alcohol Drinking & Yes & No \\
\hline Smoking & Yes & No \\
\hline
\end{tabular}

Figure7. Daily life routine 


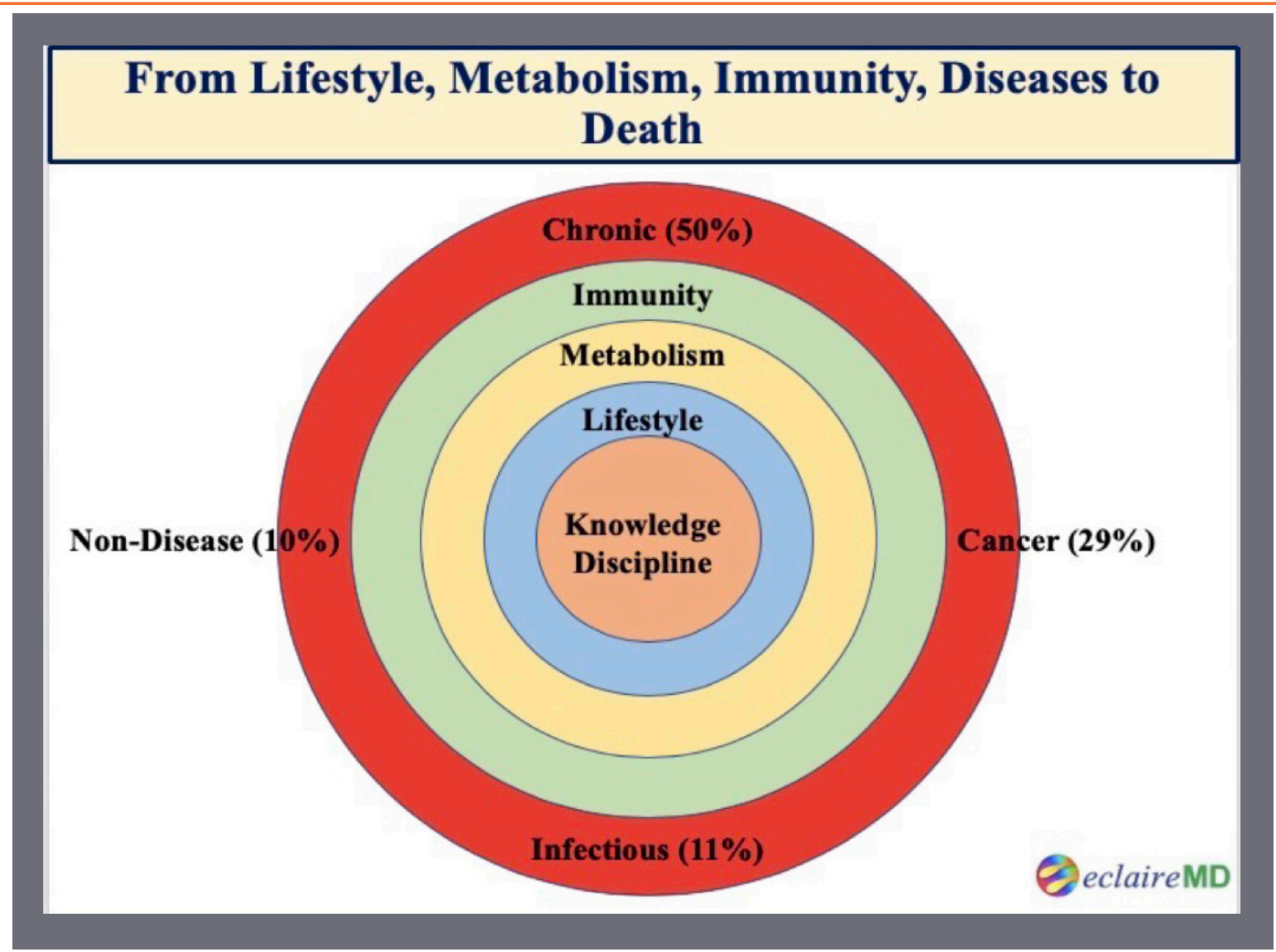

Figure8. From lifestyle through metabolism, immunity, diseases, and death

\section{CONCLUSION}

This big data analytics based on $\sim 2$ million data over 8.5 years. His developed metabolism model have shed some light about the impact on his life longevity due to his overall metabolism changes, especially including both stress level and daily life routine regularity. The significant improvements on his control on chronic diseases and complications have also contributed to his perspective of life longevity, which can be a topic scope in his other research projects.

Based on the findings from this specific analysis, the author has decided to change his forthcoming lifestyle and work on a different approach to deliver and distribute his medical research results, which does not involve a heavy travel schedule. Period E's almost perfect scores give him hope to balance different areas in his future lifestyle, in terms of how to maintain equilibrium between matters that are important to his health and diseases (physiology) and things he likes to do in his life (psychology).
His metabolism model is a highly effective tool to investigate the subject of geriatrics and longevity. Moving from the inner circle towards the outside rings, Figure 8 depicts that stringent lifestyle management leading into a good metabolism state, and then converting into a strong immunity to fight against three major disease categories such as chronic diseases and complications ( $50 \%$ of death), cancers (29\% of death), and infectious diseases $(11 \%$ of death), except for the remaining $10 \%$ of non-diseases related death cases. This is a logical way to achieve longevity which is also the core of geriatrics research branch. Readers can find more detailed information from References 1 through 4 regarding the author's previous work results in this area.

\section{REFERENCES}

[1] Hsu, Gerald C. eclaireMD Foundation, USA. April 2020. "Effective health age resulting from metabolic condition changes and lifestyle maintenance program using GH-Method: Mathphysical medicine (No. 223)." 
A Geriatric Study of Longevity Via Big Data Analytics of Metabolism, Stress and Daily Life Routine Using GH-Method: Math-Physical Medicine

[2] Hsu, Gerald C. eclaireMD Foundation, USA. immune system, and various diseases using GHApril 2020."A geriatric study of self-recovering diabetes conditions using GH-Method: Mathphysical medicine (No. 280)."

[3] Hsu, Gerald C. eclaireMD Foundation, USA. December 2019."Linkage among metabolism, Method: Math-physical medicine (No. 235)."

[4] Hsu, Gerald C. eclaireMD Foundation, USA. December 2019. "Risk probability of having a metabolic disorder induced cancer using GHMethod: Math-physical medicine (No. 263)."

Citation: Gerald C. Hsu. A Geriatric Study of Longevity Via Big Data Analytics of Metabolism, Stress and Daily Life Routine Using GH-Method: Math-Physical Medicine. Open Journal of Geriatrics. 2020; 3(1): 30-38.

Copyright: (C) 2020 Gerald C. Hsu. This is an open access article distributed under the Creative Commons Attribution License, which permits unrestricted use, distribution, and reproduction in any medium, provided the original work is properly cited. 